BULLETIN Bulletin hispanique

HISPANIQUE Université Michel de Montaigne Bordeaux

122-1 $\mid 2020$

Variations donjuanesques

Lorca, dramaturgo universal. Estudios en torno a la traducción de su teatro con motivo del CXX aniversario de su nacimiento

Granada, Editorial Comares, Colección Interlingua, 2019

Raquel García Fuentes

(2) OpenEdition

Edición electrónica

URL: http://journals.openedition.org/bulletinhispanique/11042

DOI: 10.4000/bulletinhispanique. 11042

ISSN: 1775-3821

Editor

Presses universitaires de Bordeaux

Edición impresa

Fecha de publicación: 18 junio 2020

Paginación: 376-379

ISBN: 979-10-300-0592-9

ISSN: 0007-4640

Referencia electrónica

Raquel García Fuentes, «Lorca, dramaturgo universal. Estudios en torno a la traducción de su teatro con motivo del CXX aniversario de su nacimiento», Bulletin hispanique [En línea], 122-1 | 2020, Publicado el 18 junio 2020, consultado el 19 enero 2021. URL: http://journals.openedition.org/bulletinhispanique/ 11042 ; DOI: https://doi.org/10.4000/bulletinhispanique.11042

Este documento fue generado automáticamente el 19 enero 2021.

Tous droits réservés 


\section{Lorca, dramaturgo universal. Estudios en torno a la traducción de su teatro con motivo del CXX aniversario de su nacimiento}

Granada, Editorial Comares, Colección Interlingua, 2019

Raquel García Fuentes

\section{REFERENCIA}

Lorca, dramaturgo universal. Estudios en torno a la traducción de su teatro con motivo del CXX aniversario de su nacimiento. Mohamed Saad SAAD (coord.), Granada: Editorial Comares, Colección Interlingua, 2019, 208 pp. ISBN 978-84-9045-868-6.

La nombradía de Federico García Lorca (1898-1936) lo exime de toda presentación: poeta y dramaturgo granadino de la generación del 27, que está considerado como una de las plumas más leídas de todos los tiempos. En su teatro, marcado por el dramatismo, lo visual es tan relevante como la vertiente lingüística. Sobre la traslación de su obra versará, precisamente, el monográfico que procedemos a comentar: Lorca, dramaturgo universal es el sexto volumen de la Colección de Estudios Traductológicos, impulsada por el Instituto Egipcio de Estudios Islámicos de Madrid, perteneciente a la colección Interlingua de la editorial granadina Comares. Con motivo del CXX aniversario de su nacimiento, dicho volumen recoge un interesante análisis compuesto por siete artículos, donde se analizan las principales traducciones de su dramaturgia a cinco de las lenguas más destacadas del planeta: el inglés, el francés, el alemán, el italiano y el árabe. En estas investigaciones traductológicas, se homenajea a este ilustre referente de las letras españolas desde su vinculación con el árabe, en tanto que a semejanza de sus compañeros de la generación del 27, nunca encubrió su pasión por el legado de su país y de su ciudad natal, Granada, de indudables raíces árabes. Con este 
fin, se han seleccionado las obras Bodas de Sangre, La zapatera prodigiosa, Amor de don Perlimplín con Belisa en su jardín, El público y La casa de Bernarda Alba. No obstante, debido al lugar insoslayable que juega la tragedia en su literatura, no sorprende el interés que han profesado los autores/as de este monográfico por las tragedias lorquianas. A este respecto, son tres los análisis efectuados sobre la traducción de Bodas de Sangre (1933) al alemán, al francés y al árabe.

2 La obra se inaugura con un análisis del coordinador del monográfico, Saad Mohamed Saad, de la Universidad Pablo de Olavide de Sevilla, quien examina la trascendencia de la cultura en la comprensión de Bodas de sangre traducida al árabe. Para realizar este balance, se adentra en las vicisitudes que origina su trasvase traslativo analizando los culturemas (elementos culturales), a los que escinde en tres categorías: referentes exclusivos de su cultura, símbolos culturales y expresiones con una carga connotativa especial. Tras el análisis efectuado, además de constatar que los traductores abogan en un $70 \%$ por una tendencia domesticante, se demuestra que los elementos de la primera categoría (referentes exclusivos de su cultura) son los que menos problemas de traducción presentan, pues es suficiente con proporcionar al lector la información necesaria para comprender el mensaje. Por el contrario, las dos últimas categorías, revisten mayores dificultades de trasvase y se pierden numerosos matices, dado que los referentes árabes carecen de los mismos contenidos culturales.

3 Sin distanciarnos del contexto arábigo y prosiguiendo con esta dinámica de análisis traslativo, el Prof. Dr. Ahmed Shafik, de la Universidad de Oviedo, analizará las estrategias empleadas en las traslaciones al árabe de La zapatera prodigiosa (1930). Para ello, reparará en las analogías y diferencias halladas entre las dos versiones estudiadas: las de 'Abd al-Raḥmân Badawī (1964) y Șaliḥ 'Almānī. A través de la exploración de tres aspectos: las interjecciones, los diminutivos y las unidades fraseológicas, el autor llegará a la conclusión de que ambos traductores han caído en algunas incoherencias que alteran el significado de la obra, especialmente en lo que atañe a la anulación del idiolecto característico de los personajes, y la pérdida de la comicidad y la ironía. Asimismo, en la fraseología, se advierte una nítida preferencia por la literalidad, sin hallar expresiones hechas que transmitan un sentido análogo en el texto traducido. El objetivo del Prof. Shafik es concienciar a las personas implicadas en la traducción, así como al alumnado, de los aciertos y deslices de un clásico de la literatura universal, el cual no deja de ser objeto de nuevas traslaciones.

Si nos trasladamos a la recepción de la obra lorquiana en el contexto germano, la Profa. Dra. Christiane Limbach, de la Universidad Pablo de Olavide, lleva a cabo un detallado estudio de la traslación de Bodas de sangre al alemán. En particular, ahondará en la recepción traslativa que poseyó Heinrich Enrique Beck (1904-1974), quien gozó durante décadas de los derechos exclusivos de la traducción de su obra al alemán, suscitando una oleada de críticas, hasta que, en 1999, Rudolf Wittkopf (1933-1997) efectuara una nueva traslación de la tragedia. Tras analizar las dificultades traslativas, la autora realiza un estudio contrastivo entre las dos traducciones existentes. Se concluye que las competencias traslativas de Beck están lejos del dominio del castellano de Wittkopf, lo cual le imposibilitó trasvasar adecuadamente la oralidad inmanente a toda pieza teatral, desencadenando múltiples errores traslativos. Bajo este ángulo, Limbach nos recuerda que las traducciones envejecen y que, con el transcurso del tiempo, pueden parecer anticuadas. Así, no es de extrañar que la lengua alemana y los recursos 
estilísticos empleados por Wittkopf en 1999 fuesen mucho más «modernos» que la traslación de Beck en 1952.

Daniel Nisa Cáceres seguirá esta misma estela de análisis, profundizando, por su parte, en cuatro traducciones al inglés de la farsa El amor de don Perlimplín con Belisa en su jardín (1928). Su autor considera que el carácter autoritativo del que gozó la versión de James Graham-Lujan y Richard o'Donnell obstaculizó la apreciación internacional de la pieza, en cuanto que su imposibilidad de crear un texto apto para la escena empañó sus aciertos traslativos. Una vez analizadas las cuatro traducciones, el investigador realza la competencia traductológica de David Johnston, uno de los pocos traductores que consiguió aproximarse a su proyección escénica y el único en ser capaz de imprimir la fusión entre lo lírico y lo grotesco que se pernota en la obra original. De esta aleluya erótica, el profesor Nisa también subrayará su carácter inconcluso y su indefinición textual -promovido por sus múltiples reescrituras-, hecho que, a su juicio, propiciará «nuevas y fascinantes reescrituras anglófonas» (p. 113) en los años venideros.

En el quinto capítulo, la Profa. Dra. María del Mar López-Cabrales, de Colorado State University, examina la traducción de El público por Carlos Bauer al inglés en 1986. Para ello, su análisis se centra en los culturemas y el contenido de la obra, relegando a un segundo plano otras variables como la musicalidad y la poética al estimar todo un reto hallar equivalentes en una lengua como el inglés, con un ritmo y una cadencia tan dispares al castellano. En su investigación, se exponen diversos fragmentos de $\mathrm{El}$ público, tanto en su versión original como traducida, que demuestran que la obra posee, según la autora, una imaginería intraducible para personas foráneas a la cultura andaluza. Se estima, por ende, que la mayor complejidad para traducir esta obra reside en la trasmisión en la lengua meta de los elementos culturales inherentes al sur de España. En expresión de la investigadora, mediante esta pieza, Lorca se acerca al límite de lo inefable, de lo que no se puede ni debe decir. Por este motivo, su traducción resulta casi un imposible; y su comprensión, incluso para los propios hispanohablantes, deviene un arduo desafío.

7 En el sexto artículo, el Prof. Dr. Jordi Luengo López, de la Universidad Pablo de Olavide, se adentra en la complejidad que entraña la traducción de las metáforas en tres versiones francesas de Bodas de Sangre. Éstas son las de Marcelle Auclair y colaboradores (1953), Fabrice Melquiot (2005) y Albert Bensoussan (2017). Tras un minucioso estudio comparativo, el investigador sostiene que la versión de Melquiot es la que mejor transmite el contenido de las metáforas lorquianas. Una dinámica funcional que divergirá de la primera traducción al francés, la de Marcelle Auclair, donde se omiten algunos versos completos e incluso diálogos de la obra original. La hipótesis que baraja el Dr. Luengo es que la autora no tuviera mayor pretensión que divulgar esta pieza de Lorca por primera vez al francés, sin detenerse en sus formas lingüísticas. A tenor de las apreciaciones del investigador, lo esencial al traducir es respetar la formulación lingüística de las figuras retóricas en la lengua meta, variándolas sólo en caso de que los requerimientos poéticos así lo exijan, pero nunca resignificándolas en demasía ni dejándonos llevar por un afán creativo que altere su esencia.

Para concluir, en el último estudio, Alicia María López Márquez y Francisco Molina Díaz, ambos docentes de la Universidad Pablo de Olavide, estudian los andalucismos presentes en La casa de Bernarda Alba (1945) y su traslación al italiano por Vittorio Bodini. Constatan, en primer lugar, la escasa prevalencia de estas unidades léxicas en comparación a otras obras del autor, probablemente propiciado por el hecho de que 
Lorca pretendió infundirle un carácter más neutro y universal. En cualquier caso, los autores llegan a la conclusión de que Bodini consigue trasvasar con gran maestría los términos de carácter local al italiano, habida cuenta de su patente dominio del castellano y, en específico, de la cultura andaluza.

9 Dada la proyección internacional de la obra de Federico García Lorca, el presente libro se perfila como un primer paso hacia un necesario análisis traductológico de su poesía y su producción dramatúrgica. En este interdisciplinar volumen, se pasa revista a la historia de la traducción de los clásicos lorquianos, así como a las dinámicas traslativas que predominaron en cada centuria. El presente estudio nos permite, en consecuencia, percibir más nítidamente la recepción traductológica de este clásico de las letras hispanas a cinco de las principales lenguas del planeta. Allende la profundización de sus vínculos con la cultura arábiga, nos brinda la oportunidad de ahondar en los recursos traslativos y géneros literarios a los que se tradujeron sus obras. Todo ello, sugiriéndonos alternativas de mejora por profesionales en traductología en aras de lograr traslaciones más fidedignas y apropiadas en términos de recepción emocional.

\section{AUTORES}

\section{RAQUEL GARCÍA FUENTES}

Université Sorbonne Nouvelle - Paris 3 